\title{
3 Research Square

\section{Contribution to the peripheral vasculopathy and endothelial cell dysfunction by CXCL4 in Systemic Sclerosis}

\section{Zhixing Jiang}

Huashan Hospital Fudan University

\section{Chen Chen}

Huashan Hospital Fudan University

\section{Sen Yang}

Huashan Hospital Fudan University

\section{Hang He}

Huashan Hospital Fudan University

\section{Xiaoxia Zhu}

Huashan Hospital Fudan University

\section{Minrui Liang ( $\sim$ Imr_fudan@aliyun.com )}

Huashan Hospital Fudan University https://orcid.org/0000-0002-7650-1237

\section{Research article}

Keywords: Systemic sclerosis (SSc), the very early diagnosis of SSc (VEDOSS), vasculopathy, digital ulcer, CXCL4, Fli-1

Posted Date: July 22nd, 2020

DOl: https://doi.org/10.21203/rs.3.rs-46094/v1

License: (c) (i) This work is licensed under a Creative Commons Attribution 4.0 International License.

Read Full License

Version of Record: A version of this preprint was published at Journal of Dermatological Science on July 1st, 2021. See the published version at https://doi.org/10.1016/j.jdermsci.2021.07.006. 


\section{Abstract}

\section{Objective}

CXCL4, a chemokine with antiangiogenic property, is reported to be involved in systemic sclerosis (SSc) related pulmonary arterial hypertension (PAH). We investigated the contribution of CXCL4 to SSC development by focusing on the correlation of circulatory CXCL4 levels with their peripheral vasculopathy, as well as the effect of CXCL4 on endothelial cell dysfunction and angiogenesis disturbance in SSc and the potential signaling.

\section{Methods}

We measured the serum CXCL4 levels in 58 patients with SSc, 10 patients with the very early diagnosis of SSc (VEDOSS), and 80 healthy controls. Then, CXCL4 levels were correlated with their clinical features, especially the peripheral vasculopathy. These observations were further validated in an additional cohort including 50 SSc patients, 12 VEDOSS patients, and 80 healthy controls. Moreover, we studied the antiangiogenesis effects and the underlying signaling of CXCL4 in human umbilical vein endothelial cells (HUVECs) in vitro.

\section{Results}

Circulating levels of the CXCL4 were 103.62\% higher in patients with SSc and $201.51 \%$ higher in patients with VEDOSS than matched HCs, and these observations were confirmed in two independent cohorts. CXCL4 levels were closely associated with digital ulcers (DU) and nailfold video capillaroscopy (NVC) abnormalities in SSc. The proliferation, migration, and tube formation of HUVECs were significantly inhibited by recombinant human CXCL4 or SSc derived serum, which reversed by CXCL4 neutralizing antibody, but not CXCR3 inhibitor. CXCL4 downregulated the transcription factor Friend leukaemia integration factor-1 (Fli-1) via c-Abl signaling. Furthermore, CXCL4 blocked the transforming growth factor (TGF) $-\beta$ or platelet-derived growth factor (PDGF) induced cell proliferation of HUVECs.

\section{Conclusions}

CXCL4 may contribute to peripheral vasculopathy in SSc by downregulating Fli-1 via c-Abl signaling in endothelial cells and interfering angiogenesis.

\section{Introduction}

Systemic sclerosis (SSc) is an autoimmune disease with skin and multiple viscera involvement, which characterized by a complex interplay of vasculopathy, immune system activation, and persistent tissue fibrosis[1]. Progressive and marked reduction in capillaries is a hallmark finding in early stage SSc with avascularity increasing with disease progression. Patients with SSc may develop a spectrum of vascular disease, mainly including Reynaud's phenomenon (RP), digital ulcer (DU), pulmonary arterial hypertension $(\mathrm{PAH})$, and scleroderma renal crisis (SRC). In SSc patients, the universal prevalence of RP demonstrated 
that increased vascular dysfunction exists in the process of SSc[2]. As the first onset symptom, RP leads to continuous digital ischemia, which may develop into digital ulcers (DU) or severe digital ischemia with gangrene in some extreme cases[3]. These early events induce increasing vascular tone, decreasing capillary blood flow, and chronic tissue hypoxia, ultimately leading to the extracellular matrix (ECM)[4] accumulation and tissue fibrosis. Therefore, it is necessary to identify biomarkers that could predict the very early SSc, before inevitable organ injury and fibrosis occurred.

The alteration of both pro-angiogenic mediators and inhibitors of angiogenesis have been recently implicated in vascular dysfunction in SSc[5]. In addition, impairment of angiogenic signal transduction pathways in endothelial cells contributed to disturbing angiogenesis in SSc[6]. Previous studies have focused on CXCL4 and its anti-angiogenic effects in the pathogenesis of atherosclerosis[7], and cancer[8]. Proteome-wide analysis revealed CXCL4 as a biomarker in SSc, and subsequently closely correlated with interstitial lung disease (ILD) and PAH[9]. CXCL4, unlike other chemokines that bind to their specific receptors, exerts its effects through its high affinity for proteoglycans and other negatively charged molecules. It was also reported that CXCL4 can directly bind to the CXCR3B chemokine receptor isoform or lipoprotein-related protein-1(LRP1)[11]. In patients with SSc, CXCL4 binds DNA into specific immune complexes that magnify plasmacytoid dendritic cell $(\mathrm{pDC})$-hyperactivation and produce inflammatory cytokines, which independent of CXCR3[12]. These data suggest the involvement of CXCL4 in SSc pathology.

Therefore, the aims of this study were to investigate whether the levels of CXCL4 could be altered in the very early diagnosis of SSc (VEDOSS), which manifesting typical vasculopathy but not fibrosis yet. Then, the association between the levels of CXCL4 and the peripheral vasculopathy in SSc evaluated clinically or by nailfold videocapillaroscopy (NVC) was also studied. Furthermore, we explored the potential signaling mechanism mediated by CXCL4, which could be functionally contribute to the defective angiogenic process characteristic of this disease spectrum.

\section{Method}

\section{Patients, controls and serum samples.}

In the discovery cohort, serum samples from 58 patients with systemic sclerosis (SSc)[13], 10 patients with VEDOSS[14] were collected between Jun 2016 to Jun 2018 at Huashan Hospital, Fudan University, Shanghai, China. Here, VEDOSS patients presented with RP, puffy fingers, and positivity of antinuclear antibodies, together with SSc specific antibodies and/or pathognomonic microvascular alteration at capillaroscopy, meanwhile not fulfilling the 2013 American College of Rheumatology (ACR)/ European League Against Rheumatism (EULAR) classification criteria for SSc (i.e. total score < 9)[15]. The modified Rodnan skin score (mRSS) of all included patients were assessed by the same rheumatologist $(\mathrm{ML})$ at all time points during the study period. The disease duration of SSc patients was calculated from the first non-RP symptom. Detailed definitions of the cutaneous subsets, clinical features, organ involvements, nailfold capillaroscopy patterns, and immunological features have been shown in Table 1. Eighty healthy 
controls (HCs) matched for sex and age were also included as a comparison group. The presence of primary RP was an exclusion criterion for healthy controls. An age-matched and sex-matched replication cohort consisting of 50 SSc patients, 12 VEDOSS patients, and 80 controls, was assessed between Jul 2018 to Jun 2019. The demographic and clinical characteristics of patients included in the replication cohort are summarized in Table 2.

Table 1

Demographic and clinical characteristics of the patients with SSc and VEDOSS in the discovery cohort.

\begin{tabular}{lll} 
Characteristics & SSc, $\mathbf{n}=\mathbf{5 8}$ & VEDOS \\
\hline Age, years, mean \pm SD (range) & $58.00 \pm 13.23,2-72$ & $55.70 \pm 6$. \\
Sex & & \\
Male & $14(24.14)$ & $1(10)$ \\
Female & $44(75.86)$ & $9(90)$
\end{tabular}

Disease subset

dcSSc

$24(41.38)$

IcSSc

$21(36.21)$

Overlap

10 (17.24)

SSc sine Scleroderma

3 (5.17)

Disease duration ${ }^{\text {a }}$, years, mean \pm SD (range)

$3.61 \pm 3.77, \quad 1.51 \pm 1.77$,

$0.30-18.00$

$0-5$

Autoantibody positivity

ANA

55 (94.83)

$10(100)$

ACA

11 (18.97)

8 (80)

ATA

$28(48.28)$

1 (10)

Interstitial lung disease (ILD)

38 (65.52)

$2(20)$

Digital ulcers

18 (31.03)

0

$\mathrm{mRSS}^{\mathrm{b}}$, mean $\pm \mathrm{SD}$ (range)

$10.19 \pm 10.64,0-38$

$0.10 \pm 0.32,0-1$

Except where indicated otherwise, values are the number (\%) of subjects. ${ }^{a}$ Disease duration was calculated since the first non-Raynaud's symptom of SSc; bmodified Rodnan skin thickness score. ACA, anticentromere antibodies; ANA, antinuclear antibodies; ATA, anti-topoisomerase I antibodies; dcSSc, diffuse cutaneous SSc; IcSSc, limited cutaneous SSc; SSc, systemic sclerosis; VEDOSS, very early diagnosis of SSc 
Table 2

Demographic and clinical characteristics of the patients with SSC and VEDOSS in the replication cohort.

$\begin{array}{lll}\text { Characteristics } & \text { SSc, } \mathrm{n}=\mathbf{5 0} & \text { VEDOSS, } \mathrm{n}=\mathbf{1 2}\end{array}$

Age, years, mean \pm SD (range)

$54.18 \pm 13.26,25-78 \quad 57.58 \pm 7.19,47-68$

Sex

Male

$13(26)$

$3(25)$

Female

$37(74)$

$9(75)$

Disease subset

dcSSc

$28(56)$

IcSSc

$18(36)$

Overlap

SSc sine Scleroderma

$1(2)$

Disease duration ${ }^{a}$, years, mean \pm SD (range)

$3.88 \pm 5.31,0-28$

$1.29 \pm 1.39,0-4$

Autoantibody positivity

\section{ANA}

$48(96.00)$

$12(100)$

ACA

6 (12)

8 (66.67)

ATA

$21(42)$

$2(16.67)$

Interstitial lung disease (ILD)

29 (58)

$1(8.3)$

Digital ulcers

$23(46)$

0

$\mathrm{mRSS}^{\mathrm{b}}$, mean $\pm \mathrm{SD}$ (range)

$10.48 \pm 8.34,0-31$

$0.10 \pm 0.32,0-1$

Except where indicated otherwise, values are the number (\%) of subjects. ${ }^{a}$ Disease duration was calculated since the first non-Raynaud's symptom of SSc; bmodified Rodnan skin thickness score. ACA, anticentromere antibodies; ANA, antinuclear antibodies; ATA, anti-topoisomerase I antibodies; dcSSc, diffuse cutaneous SSc; IcSSc, limited cutaneous SSc; SSc, systemic sclerosis; VEDOSS, very early diagnosis of SSc

Serum samples were obtained excluding from the participants who were given glucocorticoid, nonsteroidal anti-inflammatory drugs (NSAIDs), or systemic immunosuppressants to avoid confounding effects of these medications on clinical parameters and CXCL4 expression. Informed consent was obtained from each patient. This study was approved by the Ethics Committee of Huashan Hospital, Fudan University. Serum was collected, centrifuged, aliquoted, and stored at $-80^{\circ} \mathrm{C}$. The serum samples had undergone only 1 freeze/thaw cycles before protein measurements. All samples were measured in duplicates, in accordance with the approved guidelines and regulations. 


\section{Statistical analysis}

GraphPad Prism 5 was used to conduct statistical analysis. Normally distributed data are presented as mean $\pm S D$, unless otherwise indicated. Inter-group differences were assessed for significance using an independent two-group t-test or one-way ANOVA with the use of a Bonferroni correction. The chi-square test was used to compare clinical characteristics and CXCL4 levels between different clinical groups, as appropriate. To assess the most effective cutoff value for CXCL4, we used DeLong's method to compute a receiver-operating-characteristic $(\mathrm{ROC})$ curve. The area $( \pm \mathrm{SE})$ under the ROC curve was $0.8051 \pm$ 0.02879 ( $95 \%$ confidence interval [CI], 0.7487 to 0.8616 ; $P<0.0001$ ). The cutoff value for CXCL4 of $2797 \mathrm{ng}$ per milliliter was determined using the Youden Index (Youden index = sensitivity + specificity - 1), the sensitivity was $60 \%$, and the specificity was $95.7 \%$ at this cutoff value. Two-sided significance thresholds were used: ${ }^{*} p<0.05,{ }^{* \star} p<0.01$.

Other methods and any associated references are available in the online supplement.

\section{Result}

\section{Circulating levels of the CXCL4 are raised in the patients with SSc and the patients with a very early diagnosis of SSc (VEDOSS)}

We first examined serum CXCL4 in SSc and VEDOSS patients in the identification cohort, and evaluated the possible correlation with specific clinical features of the disease. A total of 58 patients with SSc, 10 patients not fulfilling the 2013 ACR/EULAR classification criteria for SSc (total score $<9$ ) and identified as VEDOSS (presented with Raynaud's phenomenon, puffy figures, and positivity of antinuclear antibodies, together with SSc specific antibodies and / or pathognomonic microvascular alteration at capillaroscopy), and 80 healthy controls ( $\mathrm{HC}$ ) were recruited and stratified as described in Methods. In this identification cohort, serum CXCL4 levels were $60.59 \%$ higher in patients with SSc and $132.95 \%$ higher in patients with VEDOSS than matched HC (HC: $1751 \pm 917.1$; SSc: $2812 \pm 1445$; VEDOSS: $4079 \pm$ $1978 \mathrm{ng} / \mathrm{ml} ; \mathrm{p}<0.0001$ compared with $\mathrm{HC}$ respectively; Fig. 1A). Notably, significantly higher serum CXCL4 levels were detected in the patients with VEDOSS than the patients with SSc $(p=0.0089$, Fig. 1A). These results were subsequently validated in the replication cohort, where circulating CXCL4 resulted significantly increased in SSc $(n=50)$ and in VEDOSS $(n=12)$ serum compared with control serum $(n=80)$ (HC: $1288 \pm 839.2$; SSc: $3423 \pm 1617$; VEDOSS: $5003 \pm 1814 \mathrm{ng} / \mathrm{ml} ; \mathrm{p}<0.0001$ compared with HC respectively; Fig. 1B). Similarly, further elevation of CXCL4 was detected in the patients with VEDOSS compared to the patients with SSc $(p=0.0004$, Fig. 1B).

We performed the pooled analysis by combining patients and controls from the identification and replication cohorts. Circulating CXCL4 levels were $103.62 \%$ higher in patients with SSc and $201.51 \%$ higher in the patients with VEDOSS than in healthy controls, also significantly higher in SSc patients relative to VEDOSS patients (HC: $1520 \pm 906.4$; SSc: $3095 \pm 1551$; VEDOSS: $4583 \pm 1903 \mathrm{ng} / \mathrm{ml} ; \mathrm{p}<$ 0.0001 compared with each other; Fig. 1C). 
Moreover, we found that CXCL4 levels gradually increased per group in the following order: patients with SSc sine scleroderma (sSSSc) ( $n=4)$, overlapping syndrome of SSc $(n=13)$, limited cutaneous SSc (IcSSc) $(n=39)$, diffuse cutaneous SSc (dcSSc) ( $n=52)$, and those with very early systemic sclerosis (VEDOSS) $(n=22)$ (Fig. 1D). Additionally, the level of CXCL4 was remarkably increased in VEDOSS patients rather than those in the subsets of ssSSc, overlapping, IcSSc, or dcSSc (Fig. 1D).

\section{Increased serum CXCL4 levels positively correlate to the much severer skin fibrosis and peripheral vasculopathy in SSc patients}

We next assessed the association between CXCL4 levels and the clinical phenotype in the combined cohort, and the patients with SSc were stratified as described in Methods. The levels of CXCL4 in SSc were positively correlated with their mRSS score (Fig. 2A), demonstrating that the increased CXCL4 level may implicate much severer skin fibrosis. Notably, significantly higher serum CXCL4 levels were detected in the SSc patients with digital ulcer (DU) $(n=41)$ than those without DU $(n=67)(3686 \pm 1769 v s$ $2734 \pm 1285 \mathrm{ng} / \mathrm{ml}, \mathrm{p}=0.0016$; Fig. $2 \mathrm{~B}$ ), and the levels of CXCL4 in SSc were positively correlated with the number of digital ulcers (Fig. 2C), indicating the close association of CXCL4 with peripheral microvascular involvement severity in SSc.

We also investigated whether CXCL4 could serve as a biomarker, which performed on the combined group using ROC analysis to select a threshold (Fig. 2D). Patients who had a higher baseline level of CXCL4 (over $2797 \mathrm{ng} / \mathrm{ml}$ ) had a significantly increased prevalence of newly-onset of digital ulcer in 6 months $(34.78 \%$ vs $65.22 \%$, odds ratio $6.133, \mathrm{P}=0.0335$; Fig. $2 \mathrm{E})$, with unbiased background treatments (data not shown).

Next, we stratified SSc patients according to their nailfold videocapillaroscopy (NVC) pattern and compared the CXCL4 levels between subsets, we also evaluated the possible correlation of CXCL4 levels with the mean number of nailfold capillary in the patients with SSc $(n=58)$. SSc patients with early NVC pattern demonstrated elevated serum CXCL4 levels rather than those with active or late NVC pattern $(p=0.0159$ and $p=0.0063$ for each comparison) (Fig. 2F). The levels of CXCL4 were negatively correlated with the mean number of nailfold capillary in patients with SSc (Fig. 2G).

\section{SSc derived CXCL4 disturbed angiogenesis}

It is widely reported that the stimulation with SSc sera disturbed angiogenic performance of HUVECs[1618], and, as we showed above, circulatory CXCL4 levels were raised in the patients with SSc and correlated with their peripheral vasculopathy. Thereby, we treated HUVECs using recombinant human CXCL4 or SSc sera, with or without CXCL4 neutralized antibody, in order to testify the contribution of SSc sera derived CXCL4 to the angiogenesis of endothelial cell line HUVECs, including viability, migration and tube formation.

Firstly, the addition of CXCL4 or the SSc sera to the medium of HUVECs inhibited endothelial cell proliferation determined using CCK-8 assay, which could be significantly ameliorated by antibody- 
mediated neutralization ( $* \star * P<0.001$, Fig. $3 \mathrm{~A}$ and $3 \mathrm{~B})$.

Furthermore, the stimulation with CXCL4 significantly decreased the ability of the tube formation and migration of HUVECs, which were dramatically improved by treating with anti-CXCL4 antibody $\left({ }^{*} \mathrm{P}<0.05\right.$, $\star \star \star P<0.001$, Fig. $3 \mathrm{C}$ and $3 \mathrm{D}$ ). Similarly, both of tube formation and migration was significantly impaired after challenging with $10 \%$ SSc sera, and this inhibitory effects on HUVECs were significantly reversed by pretreatment with an anti-CXCL4 antibody (Fig. 3E and 3F). Therefore, these data revealed the antiangiogenic effects of SSc derived CXCL4.

As CXCR3 mediated $\mathrm{Ca}^{2+}$ mobilization and chemotaxis in response to $\mathrm{C}-\mathrm{X}$ - $\mathrm{C}$ chemokines, including CXCL4, we also confirmed the expression of CXCR3 in HUVECs (Supplemental Fig. 1A), we thereby wondered if CXCL4 inhibited endothelial cell proliferation via its receptor CXCR3. However, the addition of AMG487, a specific antagonist of CXCR3, did not show to reverse the inhibition of cell viability, tube formation and migration induced by CXCL4 or SSc sera ( $P>0.05$ against the CXCL4 group or SSc sera group; Supplemental Fig. 1B-G). Therefore, the data showed that CXCL4 exerted its anti-angiogenic effect on HUVECs not through CXCR3.

\section{CXCL4 regulated ET-1, c-Abl/Fli-1 pathway in HUVECs}

As ET-1 increased and Fli-1 deficiency participate in SSc peripheral vasculopathy[19-21], we examine whether CXCL4 exerted its anti-angiogenic effect through these mediators. We found that CXCL4 induced the upregulation of ET-1 and downregulation of Fli-1 in a dose-dependent manner at mRNA and protein levels in HUVECs, and these changes were reversed by the pre-treatment of anti-CXCL4 antibody $\left({ }^{*} \mathrm{P}<\right.$ $0.05,{ }^{\star} \mathrm{P}<0.01,{ }^{\star * *} \mathrm{P}<0.001$; Fig. 4 A-D), but not $C X C R 3$ pharmacological inhibition $(P>0.05$; Supplemental Fig. $1 \mathrm{H}$ and $1 \mathrm{I})$.

Since the activation of c-Abl pathway is a negative regulating Fli-1 deficiency[22, 23], we initially looked at the effect of CXCL4 on the c-Abl signaling. As shown in Fig.5A, CXCL4 increased the expression of c-Abl in a dose-dependent manner, and CXCL4 neutralizing antibody inhibited the overexpression of c-Abl induced by CXCL4 ( $P<0.001$ for each comparison). Next, we showed the time course of c-Abl induction by CXCL4 treatment in HUVECs ( $P<0.001$ for each comparison; Fig. 5B). As ponatinib[24] could inhibit cAbl pathway (Fig. $5 \mathrm{C}$ ), we also investigated that ponatinib normalized the reduced levels of Fli- $1{ }^{\star} \mathrm{P}<$ $0.05,{ }^{*} \mathrm{P}<0.01, \star \star \star \mathrm{P}<0.001$; Fig. 5D and 5E). Collectively, these data suggest that CXCL4 regulates Fli-1 via c-Abl pathway in SSc vasculopathy.

\section{CXCL4 blocked the pro-angiogenic effect of TGF- $\beta$ and PDGF in HUVECs}

Numerous pro-angiogenic mediators like transforming growth factor (TGF)- $\beta$ and platelet-derived growth factor (PDGF) activated in SSc $[25,26]$. Since CXCL4 could bind to growth factors directly to exert its effect, we examine whether TGF- $\beta$ and PDGF are involved in the progressive vasculopathy of CXCL4 induced. As shown in Fig.6 A and 6B, TGF- $\beta$ and PDGF significantly induced the proliferation of HUVECs as previously reported[27-30] and the inhibitors against TGF- $\beta$ or PDGF blocked their pro-angiogenic 
effect respectively ( $P<0.0001$ for each comparison). Interestingly, the addition of CXCL4 reduced the cell proliferation of HUVECs induced by TGF- $\beta$ and PDGF, which were completely reversed by the pretreatment of the CXCL4 neutralizing antibody. These data suggested that CXCL4 exerted its antiangiogenic effect by antagonizing TGF- $\beta$ and PDGF signaling.

CXCL4 was recently recognized to induce macrophage into a specific phenotype as "M4", which typically express interleukin (IL) -6, S100A8, matrix metalloproteinase (MMP) -7 and tumor necrosis factor (TNF) $-a$, activate endothelial cells in atherosclerosis[7]. We herein studied whether CXCL4 exerted its antiangiogenic effect by shifting the phenotype of macrophage to "M4". Similar to the previous study[11], we induced THP-1 into "M4" macrophage after CXCL4 stimulation ( ${ }^{\star} \mathrm{P}<0.05$, $\star * P<0.01$, ${ }^{\star \star \star} \mathrm{P}<0.001$; Supplemental Fig. 2). The Addition of the conditional medium (CM) from "M4" induced by CXCL4 to the cultures of HUVECs did not change the expressions of ET-1 or Fli-1 ( $P>0.05$; Supplement Fig. 3 ). Moreover, when co-culturing with this "M4" macrophage (CXCL4-induced), the HUVECs did not show the changed expressions of these genes in HUVECs $(P>0.05$; Supplement Fig. 4). Hence, these results suggested that CXCL4 contributed to anti-angiogenesis independent of triggering macrophage to the "M4" phenotype.

\section{Discussion}

In this article, we provide the evidence that CXCL4 plays an important role in peripheral vasculopathy of SSc. First, we showed here that serum CXCL4 levels are significantly increased in patients with SSC and VEDOSS patients. Higher circulating CXCL4 levels associated with the microvascular abnormalities in SSc. Second, CXCL4 was found to exerts its anti-angiogenesis function in SSc, including inhibiting endothelial cells proliferation, migration, and tube formation with c-Abl/Fli-1 pathway involvement. Third, TGF- $\beta$ and PDGF signaling may participate in the anti-angiogenesis effects of CXCL4.

CXCL4, as one of the recognized anti-angiogenesis chemokines, affects anti-angiogenesis via various ways. CXCL4/PF-4 inhibits endothelial cell proliferation[31] and migration[32], and thus displays antitumoral activity by inhibiting tumor growth[33] and suppressing the formation of metastasis[34]. In SSc patients, the serum level of CXCL4 is positively correlated with PAH[35], suggesting that CXCL4 may be involved in SSc vasculopathy. Similar to previous studies, we found that exogenous CXCL4 can effectively inhibit angiogenesis on HUVECs, including cell viability, migration, and tube formation. Notably, we demonstrated that the ability of serum from SSc patients to inhibit angiogenesis was largely dependent on CXCL4 in HUVECs, as the addition of anti-CXCL4 almost completely reverted antiangiogenesis following serum stimulation.

As the mechanism of CXCL4 in SSc vascular lesions is not yet clear, we selected two related factors of vascular mediators, i.e. ET-1 and Fli-1, and further explored the usability of anti-CXCL4 as a possible therapeutic target in SSc vasculopathy. In vitro, we found that CXCL4 and SSc patient serum could increase the expression of ET-1 and decrease Fli-1, and anti-CXCL4 could significantly reverse these effects. In this respect, the downregulation of Fli-1 is concentrated, since the elective endothelial cell 
deletion of Fli-1 in mice models leads to a disorganized dermal vascular network with greatly compromised vessel integrity and markedly increased vessel permeability[36]. Fli-1 deficiency is also related with the vasculature dysfunction in SSc[37]. Importantly, in HDMECs gene silencing of Fli-1 modulates the expression of various genes, including VE-Cadherin, PECAM1, MMP9, cathepsin B, and cathepsin V, towards an SSc EC phenotype[38-40]. These findings have explained the existence of high levels of pro-angiogenic factors in SSc patients, as well as the presence of anti-angiogenic factors like CXCL4. The imbalance of pro- and antiangiogenic factors might explain the pathogenetic mechanisms of SSc vasculopathy.

Since c-Abl pathway negatively regulates the expression of Fli-1[22], we then put forward to explore the mechanism of Fli- 1 deficiency via c-Abl after CXCL4 treatment. We found that the c-Abl pathway was activated under CXCL4 treatment. Furthermore, inhibited c-Abl kinase activity could reverse the decreased expression of Fli-1 in HUVECs. These findings are also supported by a recent study, which shows that blocking c-Abl kinase activity or decreasing the expression of c-Abl upregulates Fli-1 on SSc fibroblasts[41]. In fact, c-Abl kinase inhibition like imatinib mesylate is enrolled in dcSSc clinical trials. 1 year of treatment with imatinib significantly improved forced vital capacity (FVC) and mRSS in patients with dcSSc[42]. However, imatinib is poorly tolerated and thus limits its application in SSc[43]. In this respect, it is critical to find other small-molecules as targeted drugs for SSc. Thus, our study provides direct evidence that CXCL4 participates in SSc pathogenesis, and suggests targeting this cytokine as a potential therapeutic strategy for SSc.

A previous study demonstrated that CXCL4 could exert its effect through multiple ways, including binding to its specific receptors or other growth factors[44]. Our data suggest that although CXCR3 is expressed on HUVECs, blocking CXCR3 did not affect the anti-angiogenic effects of CXCL4. Furthermore, a quantity of evidence suggested that growth factors TGF- $\beta$ and PDGF play important roles in vasculopathy of SSc[25, 26]. Thus, we hypothesis that CXCL4 may directly bind to these growth factors and then exerts its effects in SSc vasculopathy. As shown in Fig. 6, TGF- $\beta$ and PDGF can effectively promote endothelial cell proliferation as previously reported[25, 26]. However, the angiogenic effects of TGF- $\beta$ and PDGF were significantly reversed after CXCL4 pretreatment. Taken together, our data suggested that CXCL4 may directly binding to TGF- $\beta$ and PDGF in SSc.

CXCL4 not only exerts its anti-angiogenesis ability in SSc, but also activates immune cells, including dendritic cells[45], T cell[46], neutrophil[47], mast cell[48], and macrophage[49] according to many studies, thus widely participate in the pathogenesis of various diseases. For example, CXCL4 induces monocyte differentiation resulting in a macrophage phenotype called 'M4', which especially expresses MMP7 and S100A8. 'M4' is distinct from M1 and M2 macrophages, presenting proinflammatory and cytotoxicity, reduce LDL-uptake in atherosclerosis[7, 50,51]. In SSc, CXCL4 can drive fibroblast activation indirectly via PDGF-BB production by macrophage. However, in vascular endothelial cells, it is still unclear whether CXCL4 can regulate angiogenesis by inducing macrophages. In this study, although M4 macrophages have been induced at $7 \mu \mathrm{g} / \mathrm{ml}$ of CXCL4 as previously reported[51], neither the 'M4' macrophageendothelial cell co-culture system nor the endothelial cells cultured with 'M4' macrophage CM have an 
effect on the related vascular mediators of SSc. Concerning the fact that we still need further experiments to confirm that 'M4' macrophages do exist in SSc patients, we cautiously conclude that CXCL4's involvement in SSc vasculopathy may not depend on the activation of macrophages.

Since the SSc CXCL4 serum level reaches $2000-5000 \mathrm{ng} / \mathrm{ml}$ in our current study, it can be considered that the release amount in platelet aggregates is much higher. In view of this, the relatively high $20 \mathrm{ng} / \mathrm{ml} \mathrm{CXCL4}$ threshold for inducing anti-angiogenic effects can be used to prevent the release of platelets from low concentrations of chemokines, thereby preventing accidental activation of macrophages[52]. In our study, $20 \mathrm{ng} / \mathrm{ml}$ CXCL4 may inhibit the endothelial cell proliferation, but $7 \mu \mathrm{g} / \mathrm{ml}$ CXCL4 was needed in M4 macrophage polarization. This discrepancy may be attributable to the different sensitivity of these two different cells to CXCL4. A higher concentration is required to exert the effect when CXCL4 mediates rapid processes such as macrophage activation, while this concentration became lower when CXCL4 is involved in multistep differentiation processes such as angiogenesis[53]. However, the mechanism of these phenomena still remains to be further investigated.

The possible pathobiological role of CXCL4 in fibrosis of SSc was highly proved in the previous studies $[12,54,55]$. For example, serum CXCL4 levels were significantly increased in SSc and served as a marker of lung fibrosis[10]. Consistent with these works, we observed mRSS scores positively correlated with CXCL4 levels, suggesting CXCL4 may indicate much severer skin fibrosis in SSc.

The association of circulating CXCL4 levels with peripheral vasculopathy in patients with VEDOSS also deserves discussion. In fact, we strongly put forward that CXCL4 could serve as a biomarker in VEDOSS. Firstly, we found that serum CXCL4 levels were significantly increased in patients with VEDOSS compared with all subsets of SSc, which is similar to other researches[15, 56,57]. Secondly, our data suggested that the abnormal NVC pattern and DUs were positively correlated with CXCL4 levels. Finally, CXCL4 could predict new DU in an expected cohort for 6 months. Given that the abnormal NVC pattern and DUs are the most prominent clinical symptoms reflecting pathologically activated angiogenesis in VEDOSS, it suggested that CXCL4 may be a helpful biomarker in VEDOSS patients.

Beyond the abovementioned achievements, there is still a limitation in this study. Although we revealed that CXCL4 can regulate the c-Abl pathway to reduce the expression of Fli-1, more experiments are required to further validate our findings in vivo and in vitro. In fact, c-Abl activation sequentially decreased the nuclear localization of PKC- $\delta$ and Fli-1 phosphorylation at threonine 312, and eventually leading to Fli1 deficiency. Considering the commercial factors and intellectual property issues in obtaining Fli-1 phosphorylated protein, it is not available for us to further explore the downstream activation of the c-Abl pathway. However, Akamata et al. demonstrated that activation of the c-Abl/ /PKC- $\delta / p F l i-1$ pathway reduced the level of Fli- 1 protein in fibroblasts, epithelial cells, endothelial cells, and in SSc animal models[36, 41, 58]. An alternative research perspective, which only explores the activation of the c-Abl pathway, could be adopted in investigating Fli-1 deficiency in SSc.

\section{Conclusion}


We documented a series of data confirming a possible contribution of CXCL4 to the development of vasculopathy in SSc. CXCL4 may serve as a biomarker in VEDOSS patients. Moreover, CXCL4 is likely to be involved in endothelial cell dysfunction, leading to the development of vasculopathy in SSc. The involvement of the Fli-1 pathway further supports the notion that CXCL4 is a critical anti-angiogenetic factor of SSc.

\section{Abbreviations}

SSc

Systemic sclerosis

$\mathrm{PAH}$

Pulmonary arterial hypertension

VEDOSS

Very early diagnosis of systemic sclerosis

HUVECs

Human umbilical vein endothelial cells

DU

Digital ulcers

NVC

Nailfold video capillaroscopy

Fli-1

Friend leukaemia integration factor-1

TGF

Transforming growth factor

PDGF

Platelet-derived growth factor

RP

Reynaud's phenomenon

SRC

Scleroderma renal crisis

ECM

Extracellular matrix

ILD

Interstitial lung disease

LRP1

Lipoprotein-related protein-1

pDC

Plasmacytoid dendritic cell

ACR

American College of Rheumatology 
EULAR

European League Against Rheumatism

mRSS

Modified Rodnan skin score

HCs

Healthy controls

NSAIDs

Nonsteroidal anti-inflammatory drugs

ROC

Receiver-operating-characteristic

ssSSc

Sine scleroderma

IcSSc

Limited cutaneous systemic sclerosis

dcSSc

Diffuse cutaneous systemic sclerosis

ET

Endothelin

IL

Interleukin

MMP

Matrix metalloproteinase

TNF

Tumor necrosis factor

ETAR

Endothelin A receptor

AT1R

Angiotensin type 1 receptor

FVC

forced vital capacity

ELISA

Enzyme-linked immunosorbent assay

CCK8

Cell counting kit-8

RT-qPCR

Real-time polymerase chain reaction

CM

Conditional medium

\section{Declarations}




\section{Ethics declarations}

Informed consent was obtained from each patient. This study was approved by the Ethics Committee of Huashan Hospital, Fudan University.

\section{Consent for publication}

Not applicable.

\section{Availability of data and material}

Our supporting data are available.

\section{Competing interests}

The data presented in this manuscript are original and have not been published or submitted elsewhere. All listed authors have approved the manuscript and agreed with the submission. The authors declare that they have no conflict of interest.

\section{Funding}

This work was supported by the National Natural Science Foundation of China Grant 81501391 (to M.L.), Shanghai Hospital Development Center 120166227 (to X. Z.).

\section{Author's Contributions}

ZJ, CC and SY carried out the in vitro studies. XZ and ML were responsible for the pathological assessment. $\mathrm{ML}$ and $\mathrm{HH}$ performed the statistical analysis and interpreted the data. $\mathrm{ZJ}$ and $\mathrm{ML}$ wrote the paper. $\mathrm{HH}, \mathrm{XZ}$ and $\mathrm{ML}$ conceived of the study, and participated in its design and coordination and helped to draft the manuscript. All authors have read and approved the final manuscript.

\section{Acknowledgements}

Not applicable.

\section{References}

1. Trojanowska M. Cellular and molecular aspects of vascular dysfunction in systemic sclerosis. Nature reviews Rheumatology. 2010;6(8):453-60.

2. Van Den Hoogen F, Khanna D, Fransen J, Johnson SR, Baron M, Tyndall A, Matucci-Cerinic M, Naden RP, Medsger TA Jr, Carreira PE. 2013 classification criteria for systemic sclerosis: an American College of Rheumatology/European League against Rheumatism collaborative initiative. Arthr Rhuem. 2013;65(11):2737-47. 
3. Bellando-Randone S, Matucci-Cerinic M. Very early systemic sclerosis and pre-systemic sclerosis: definition, recognition, clinical relevance and future directions. Curr Rheumatol Rep. 2017;19(10):65.

4. Matucci-Cerinic M, Manetti M, Bruni C, Chora I, Bellando-Randone S, Lepri G, De Paulis A, Guiducci S. The "myth" of loss of angiogenesis in systemic sclerosis: a pivotal early pathogenetic process or just a late unavoidable event? Arthritis research therapy. 2017;19(1):162.

5. Rabquer BJ, Koch AE. Angiogenesis and vasculopathy in systemic sclerosis: evolving concepts. Curr Rheumatol Rep. 2012;14(1):56-63.

6. Gyftaki-Venieri DA, Abraham DJ, Ponticos M. Insights into myofibroblasts and their activation in scleroderma: opportunities for therapy? Curr Opin Rheumatol. 2018;30(6):581-7.

7. Domschke G, Gleissner CA. CXCL4-induced macrophages in human atherosclerosis. Cytokine. 2019;122:154141.

8. Ruytinx P, Proost P, Struyf S. CXCL4 and CXCL4L1 in cancer. Cytokine. 2018;109:65-71.

9. Volkmann ER, Tashkin DP, Roth MD, Clements PJ, Khanna D, Furst DE, Mayes M, Charles J, Tseng CH, Elashoff RM, et al. Changes in plasma CXCL4 levels are associated with improvements in lung function in patients receiving immunosuppressive therapy for systemic sclerosis-related interstitial lung disease. Arthritis Res Ther. 2016;18(1):305.

10. van Bon L, Affandi AJ, Broen J, Christmann RB, Marijnissen RJ, Stawski L, Farina GA, Stifano G, Mathes AL, Cossu M, et al. Proteome-wide analysis and CXCL4 as a biomarker in systemic sclerosis. Arthritis Res Ther. 2014;370(5):433-43.

11. Aidoudi S, Bikfalvi A. Interaction of PF4 (CXCL4) with the vasculature: a role in atherosclerosis and angiogenesis. Thromb Haemost. 2010;104(5):941-8.

12. Lande R, Lee EY. CXCL4 assembles DNA into liquid crystalline complexes to amplify TLR9-mediated interferon-alpha production in systemic sclerosis. 2019, 10(1):1731.

13. van den Hoogen F, Khanna D, Fransen J, Johnson SR, Baron M, Tyndall A, Matucci-Cerinic M, Naden RP, Medsger TA Jr, Carreira PE, et al. 2013 classification criteria for systemic sclerosis: an American college of rheumatology/European league against rheumatism collaborative initiative. Ann Rheum Dis. 2013;72(11):1747-55.

14. Avouac J, Fransen J, Walker UA, Riccieri V, Smith V, Muller C, Miniati I, Tarner IH, Randone SB, Cutolo $M$, et al. Preliminary criteria for the very early diagnosis of systemic sclerosis: results of a Delphi Consensus Study from EULAR Scleroderma Trials and Research Group. Ann Rheum Dis. 2011;70(3):476-81.

15. Minier T, Guiducci S, Bellando-Randone S, Bruni C, Lepri G, Czirjak L, Distler O, Walker UA, Fransen J, Allanore $\mathrm{Y}$, et al. Preliminary analysis of the very early diagnosis of systemic sclerosis (VEDOSS) EUSTAR multicentre study: evidence for puffy fingers as a pivotal sign for suspicion of systemic sclerosis. Ann Rheum Dis. 2014;73(12):2087-93.

16. Avouac J, Wipff J, Goldman O, Ruiz B, Couraud PO, Chiocchia G, Kahan A, Boileau C, Uzan G, Allanore Y. Angiogenesis in systemic sclerosis: impaired expression of vascular endothelial growth factor 
receptor 1 in endothelial progenitor-derived cells under hypoxic conditions. Arthritis rheumatism. 2008;58(11):3550-61.

17. Ihn H, Sato S, Fujimoto M, Igarashi A, Yazawa N, Kubo M, Kikuchi K, Takehara K, Tamaki K. Characterization of autoantibodies to endothelial cells in systemic sclerosis (SSc): association with pulmonary fibrosis. Clin Exp Immunol. 2000;119(1):203-9.

18. Xing X, Yang J, Yang X, Wei Y, Zhu L, Gao D, Li M. IL-17A induces endothelial inflammation in systemic sclerosis via the ERK signaling pathway. PloS one. 2013;8(12):e85032.

19. Cardillo C, Schinzari F, Melina D, Mores N, Bosello S, Peluso G, Zoli A, Ferraccioli G. Improved endothelial function after endothelin receptor blockade in patients with systemic sclerosis. Arthritis rheumatism. 2009;60(6):1840-4.

20. Silva I, Teixeira A, Oliveira J, Almeida I, Almeida R, Águas A, Vasconcelos C: Endothelial Dysfunction and Nailfold Videocapillaroscopy Pattern as Predictors of Digital Ulcers in Systemic Sclerosis: a Cohort Study and Review of the Literature. Clinical reviews in allergy \& immunology 2015, 49(2):240-252.

21. Miyagawa T, Taniguchi T, Saigusa R, Fukayama M, Takahashi T, Yamashita T, Hirabayashi M, Miura $\mathrm{S}$, Nakamura K, Yoshizaki A: Fli1 deficiency induces endothelial adipsin expression, contributing to the onset of pulmonary arterial hypertension in systemic sclerosis. Rheumatology 2019.

22. Miyagawa T, Ichimura Y, Nakamura K, Hirabayashi M, Yamashita T, Saigusa R, Miura S, Takahashi T, Toyama T, Taniguchi T, et al. Progranulin overproduction due to constitutively activated c-Abl/PKC$\delta / F l i 1$ pathway contributes to the resistance of dermal fibroblasts to the anti-fibrotic effect of tumor necrosis factor-a in localized scleroderma. J Dermatol Sci. 2018;92(2):207-14.

23. Akamata K, Asano Y, Yamashita T, Noda S, Taniguchi T, Takahashi T, Ichimura Y, Toyama T, Trojanowska M, Sato S. Endothelin receptor blockade ameliorates vascular fragility in endothelial cell-specific Fli-1-knockout mice by increasing Fli-1 DNA binding ability. Arthritis rheumatology (Hoboken NJ). 2015;67(5):1335-44.

24. Pemovska T, Johnson E, Kontro M, Repasky GA, Chen J, Wells P, Cronin CN, McTigue M, Kallioniemi O, Porkka K, et al. Axitinib effectively inhibits BCR-ABL1(T315I) with a distinct binding conformation. Nature. 2015;519(7541):102-5.

25. Liakouli V, Cipriani P, Marrelli A, Alvaro S, Ruscitti P, Giacomelli R. Angiogenic cytokines and growth factors in systemic sclerosis. Autoimmun rev. 2011;10(10):590-4.

26. Riccieri V, Stefanantoni K, Vasile M, Macrí V, Sciarra I, lannace N, Alessandri C, Valesini G. Abnormal plasma levels of different angiogenic molecules are associated with different clinical manifestations in patients with systemic sclerosis. Clinical Experimental Rheumatology-Incl Supplements. 2011;29(2):46.

27. Pepper MS. Transforming growth factor-beta: vasculogenesis, angiogenesis, and vessel wall integrity. Cytokine Growth Factor Rev. 1997;8(1):21-43.

28. Pardali E, ten Dijke P. Transforming growth factor-beta signaling and tumor angiogenesis. Front Biosci. 2009;14:4848-61. 
29. Battegay EJ, Rupp J, Iruela-Arispe L, Sage EH, Pech M. PDGF-BB modulates endothelial proliferation and angiogenesis in vitro via PDGF beta-receptors. J Cell Biol. 1994;125(4):917-28.

30. Cao R, Bråkenhielm E, Pawliuk R, Wariaro D, Post MJ, Wahlberg E, Leboulch P, Cao Y. Angiogenic synergism, vascular stability and improvement of hind-limb ischemia by a combination of PDGF-BB and FGF-2. Nature medicine. 2003;9(5):604-13.

31. Wang Z, Huang H. Platelet factor-4 (CXCL4/PF-4): an angiostatic chemokine for cancer therapy. Cancer letters. 2013;331(2):147-53.

32. Sharpe RJ, Byers HR, Scott CF, Bauer SI, Maione TE. Growth inhibition of murine melanoma and human colon carcinoma by recombinant human platelet factor 4 . JNCl: Journal of the National Cancer Institute. 1990;82(10):848-53.

33. Maione TE, Gray GS, Petro J, Hunt AJ, Donner AL, Bauer SI, Carson HF, Sharpe RJ. Inhibition of angiogenesis by recombinant human platelet factor-4 and related peptides. Science. 1990;247(4938):77-9.

34. Kolber DL, Knisely TL, Maione TE. Inhibition of development of murine melanoma lung metastases by systemic administration of recombinant platelet factor 4 . JNCl: Journal of the National Cancer Institute. 1995;87(4):304-9.

35. van Bon L, Affandi AJ, Broen J, Christmann RB, Marijnissen RJ, Stawski L, Farina GA, Stifano G, Mathes AL, Cossu M. Proteome-wide analysis and CXCL4 as a biomarker in systemic sclerosis. New England journal of medicine. 2014;370(5):433-43.

36. Akamata K, Asano Y, Yamashita T, Noda S, Taniguchi T, Takahashi T, Ichimura Y, Toyama T, Trojanowska M, Sato S. Endothelin Receptor Blockade Ameliorates Vascular Fragility in Endothelial Cell-Specific Fli-1-Knockout Mice by Increasing Fli-1 DNA Binding Ability. Arthritis Rheumatology. 2015;67(5):1335-44.

37. Takahashi T, Asano Y, Sugawara K, Yamashita T, Nakamura K, Saigusa R, Ichimura Y, Toyama T, Taniguchi T, Akamata K, et al. Epithelial Fli1 deficiency drives systemic autoimmunity and fibrosis: Possible roles in scleroderma. The Journal of experimental medicine. 2017;214(4):1129-51.

38. Asano Y, Stawski L, Hant F, Highland K, Silver R, Szalai G, Watson DK, Trojanowska M. Endothelial Fli1 deficiency impairs vascular homeostasis: a role in scleroderma vasculopathy. Am J Pathol. 2010;176(4):1983-98.

39. Noda S, Asano Y, Akamata K, Aozasa N, Taniguchi T, Takahashi T, Ichimura Y, Toyama T, Sumida H, Yanaba K. A possible contribution of altered cathepsin B expression to the development of skin sclerosis and vasculopathy in systemic sclerosis. PloS one. 2012;7(2):e32272.

40. Noda S, Asano Y, Takahashi T, Akamata K, Aozasa N, Taniguchi T, Ichimura Y, Toyama T, Sumida H, Kuwano Y. Decreased cathepsin V expression due to Fli1 deficiency contributes to the development of dermal fibrosis and proliferative vasculopathy in systemic sclerosis. Rheumatology. 2013;52(5):790-9.

41. Akamata K, Asano Y, Aozasa N, Noda S, Taniguchi T, Takahashi T, Ichimura Y, Toyama T, Sato S. Bosentan reverses the pro-fibrotic phenotype of systemic sclerosis dermal fibroblasts via increasing 
DNA binding ability of transcription factor Fli1. Arthritis Res Ther. 2014;16(2):R86.

42. Spiera RF, Gordon JK, Mersten JN, Magro CM, Mehta M, Wildman HF, Kloiber S, Kirou KA, Lyman S, Crow MK. Imatinib mesylate (Gleevec) in the treatment of diffuse cutaneous systemic sclerosis: results of a 1-year, phase lla, single-arm, open-label clinical trial. Ann Rheum Dis. 2011;70(6):1003-9.

43. Pope J, McBain D, Petrlich L, Watson S, Vanderhoek L, de Leon F, Seney S, Summers K. Imatinib in active diffuse cutaneous systemic sclerosis: results of a six-month, randomized, double-blind, placebo-controlled, proof-of-concept pilot study at a single center. Arthr Rhuem. 2011;63(11):354751.

44. Quemener C, Baud J, Boyé K, Dubrac A, Billottet C, Soulet F, Darlot F, Dumartin L, Sire M, Grepin R. Dual roles for CXCL4 chemokines and CXCR3 in angiogenesis and invasion of pancreatic cancer. Cancer research. 2016;76(22):6507-19.

45. Ah Kioon MD, Tripodo C, Fernandez D, Kirou KA, Spiera RF, Crow MK, Gordon JK, Barrat FJ: Plasmacytoid dendritic cells promote systemic sclerosis with a key role for TLR8. Science translational medicine 2018, 10(423).

46. Affandi AJ, Silva-Cardoso SC, Garcia S, Leijten EFA, van Kempen TS, Marut W, van Roon JAG, Radstake T. CXCL4 is a novel inducer of human Th17 cells and correlates with IL-17 and IL-22 in psoriatic arthritis. Eur J Immunol. 2018;48(3):522-31.

47. Wetterholm E, Linders J, Merza M, Regner S, Thorlacius H. Platelet-derived CXCL4 regulates neutrophil infiltration and tissue damage in severe acute pancreatitis. Translational Research. 2016;176:105-18.

48. Schiemann F, Brandt E, Gross R, Lindner B, Mittelstädt J, Sommerhoff CP, Schulmistrat J, Petersen F. The cathelicidin LL-37 activates human mast cells and is degraded by mast cell tryptase: counterregulation by CXCL4. J Immunol. 2009;183(4):2223-31.

49. Yeo L, Adlard N, Biehl M, Juarez M, Smallie T, Snow M, Buckley C, Raza K, Filer A, Scheel-Toellner D. Expression of chemokines CXCL4 and CXCL7 by synovial macrophages defines an early stage of rheumatoid arthritis. Ann Rheum Dis. 2016;75(4):763-71.

50. von Hundelshausen P, Schmitt MM. Platelets and their chemokines in atherosclerosis-clinical applications. Frontiers in physiology. 2014;5:294.

51. Erbel C, Wolf A, Lasitschka F, Linden F, Domschke G, Akhavanpoor M, Doesch AO, Katus HA, Gleissner CA. Prevalence of M4 macrophages within human coronary atherosclerotic plaques is associated with features of plaque instability. Int J Cardiol. 2015;186:219-25.

52. Woller G, Brandt E, Mittelstädt J, Rybakowski C, Petersen F. Platelet factor 4/CXCL4-stimulated human monocytes induce apoptosis in endothelial cells by the release of oxygen radicals. J Leukoc Biol. 2008;83(4):936-45.

53. Vandercappellen J, Van Damme J, Struyf S. The role of the CXC chemokines platelet factor-4 (CXCL4/PF-4) and its variant (CXCL4L1/PF-4var) in inflammation, angiogenesis and cancer. Cytokine \& growth factor reviews 2011, 22(1). 
54. Palazzo R, Marinari B, Pietraforte I, Santos GS, Mattenberger Y, Spadaro F, Stefanantoni K, lannace N, Dufour AM, Falchi M, et al. CXCL4 Exposure Potentiates TLR-Driven Polarization of Human Monocyte-Derived Dendritic Cells and Increases Stimulation of T Cells. Nature communications. 2017;199(1):253-62.

55. Spel L, Cossu M, van Roon JAG, Boes M, Radstake T, van Bon L, Cossu M, Scharstuhl A, Pennings $B W$, Vonk MC, et al: Low heme oxygenase-1 levels in patients with systemic sclerosis are associated with an altered Toll-like receptor response: another role for CXCL4? Journal of immunology (Baltimore, Md: 1950) 2016, 55(11):2066-2073.

56. Romano E, Manetti M. Slit2/Robo4 axis may contribute to endothelial cell dysfunction and angiogenesis disturbance in systemic sclerosis. 2018, 77(11):1665-1674.

57. Lepri G, Guiducci S, Bellando-Randone S, Giani I, Bruni C, Blagojevic J, Carnesecchi G, Radicati A, Pucciani F, Marco MC. Evidence for oesophageal and anorectal involvement in very early systemic sclerosis (VEDOSS): report from a single VEDOSS/EUSTAR centre. Ann Rheum Dis. 2015;74(1):1248.

58. Akamata K, Asano Y, Taniguchi T, Yamashita T, Saigusa R, Nakamura K, Noda S, Aozasa N, Toyama $\mathrm{T}$, Takahashi T, et al. Increased expression of chemerin in endothelial cells due to Fli1 deficiency may contribute to the development of digital ulcers in systemic sclerosis. Rheumatology. 2015;54(7):1308-16.

\section{Figures}



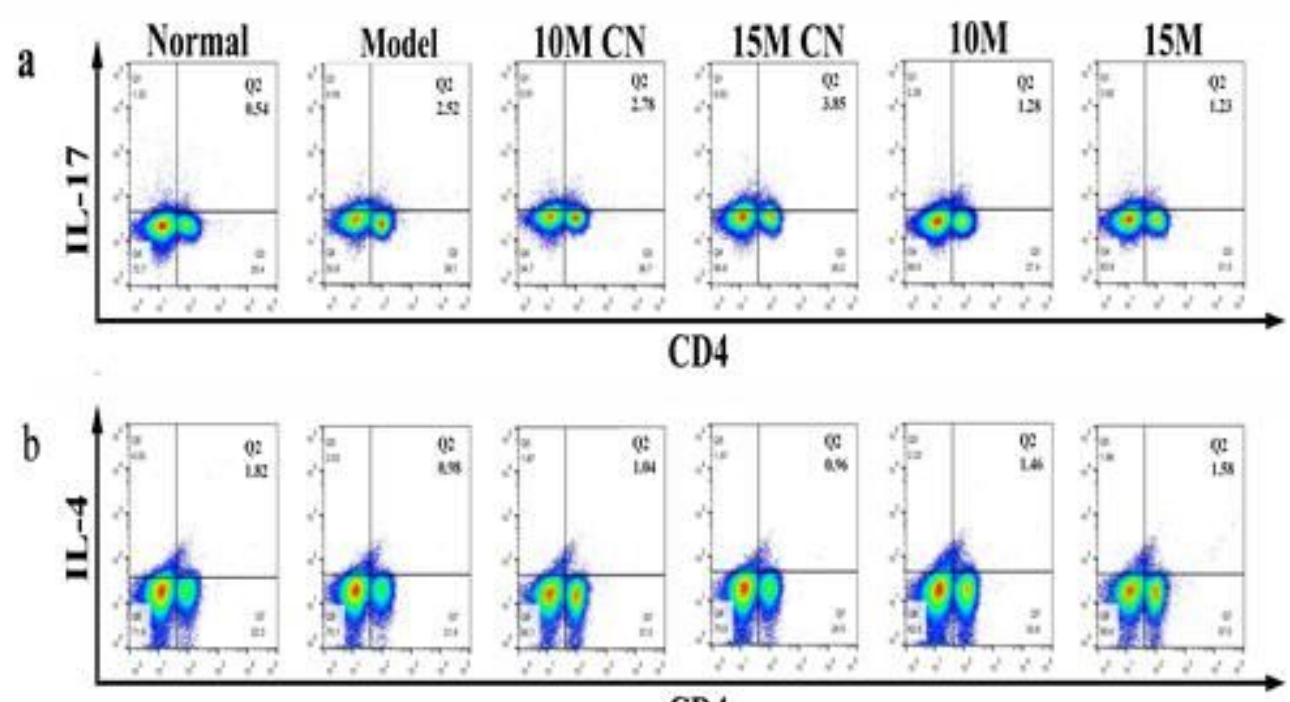

\section{CD4}
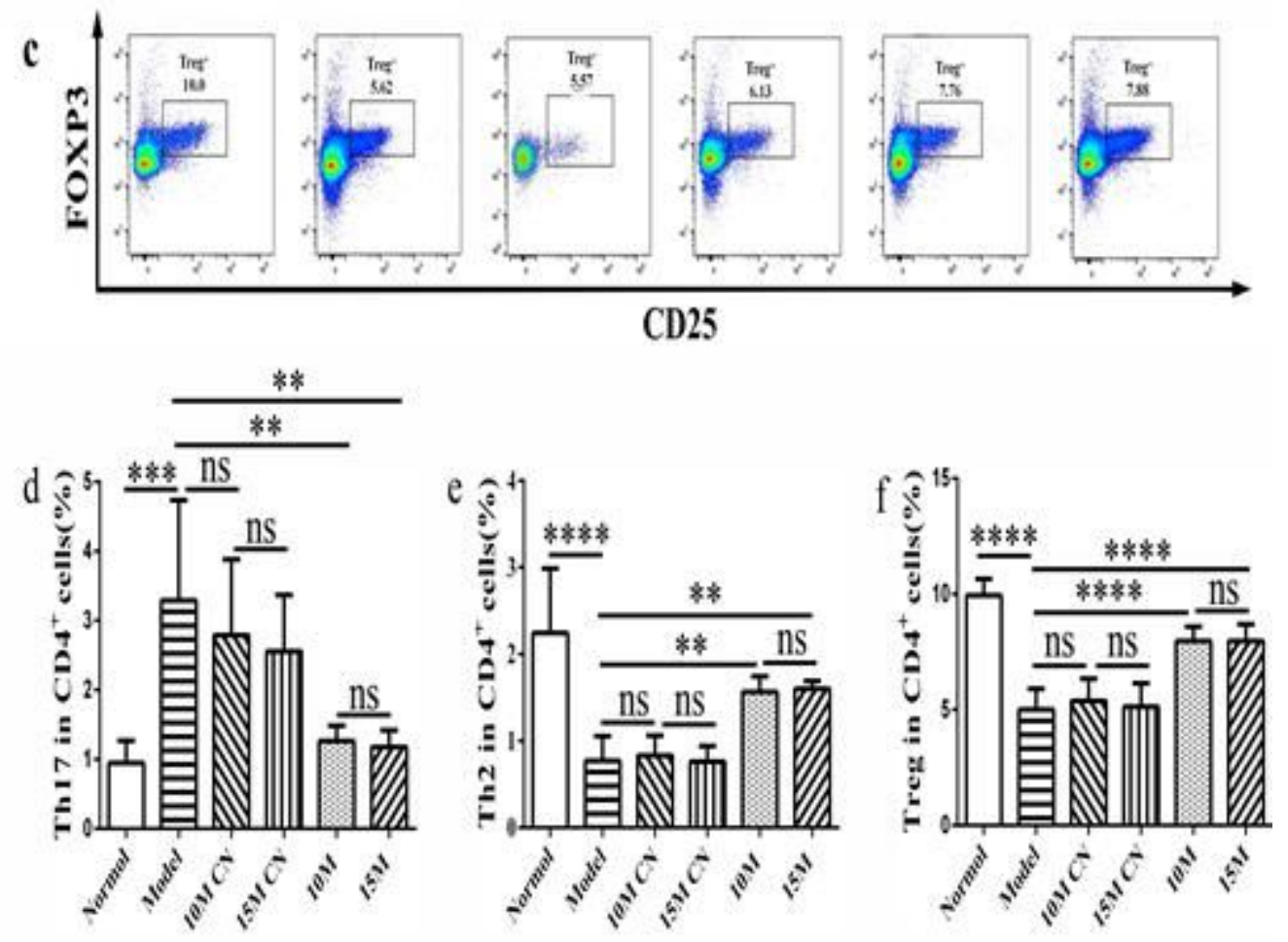

\section{Figure 1}

CXCL4 sera levels detected by ELISA assay. (A-C) Serum CXCL4 levels in health controls (HC), patients with systemic sclerosis (SSc) and patients not fulfilling the 2013 American College of Rheumatology (ACR) /European League Against Rheumatism (EULAR) classification criteria for SSc and enrolled in the very early diagnosis of SSc (VEDOSS) project. Results from the identification (A), replication (B), and combined (C) cohorts are shown. (D) Serum CXCL4 levels in total HC and patients with SSc sine scleroderma (ssSSc) $(n=4)$, overlapping syndrome of SSc $(n=13)$, limited cutaneous systemic sclerosis (IcSSc) ( $n=39)$, diffuse cutaneous systemic sclerosis (dcSSc) $(n=52)$, and those with very early systemic sclerosis (VEDOSS) $(n=22) .\left({ }^{\star * *} p<0.001\right)$ 

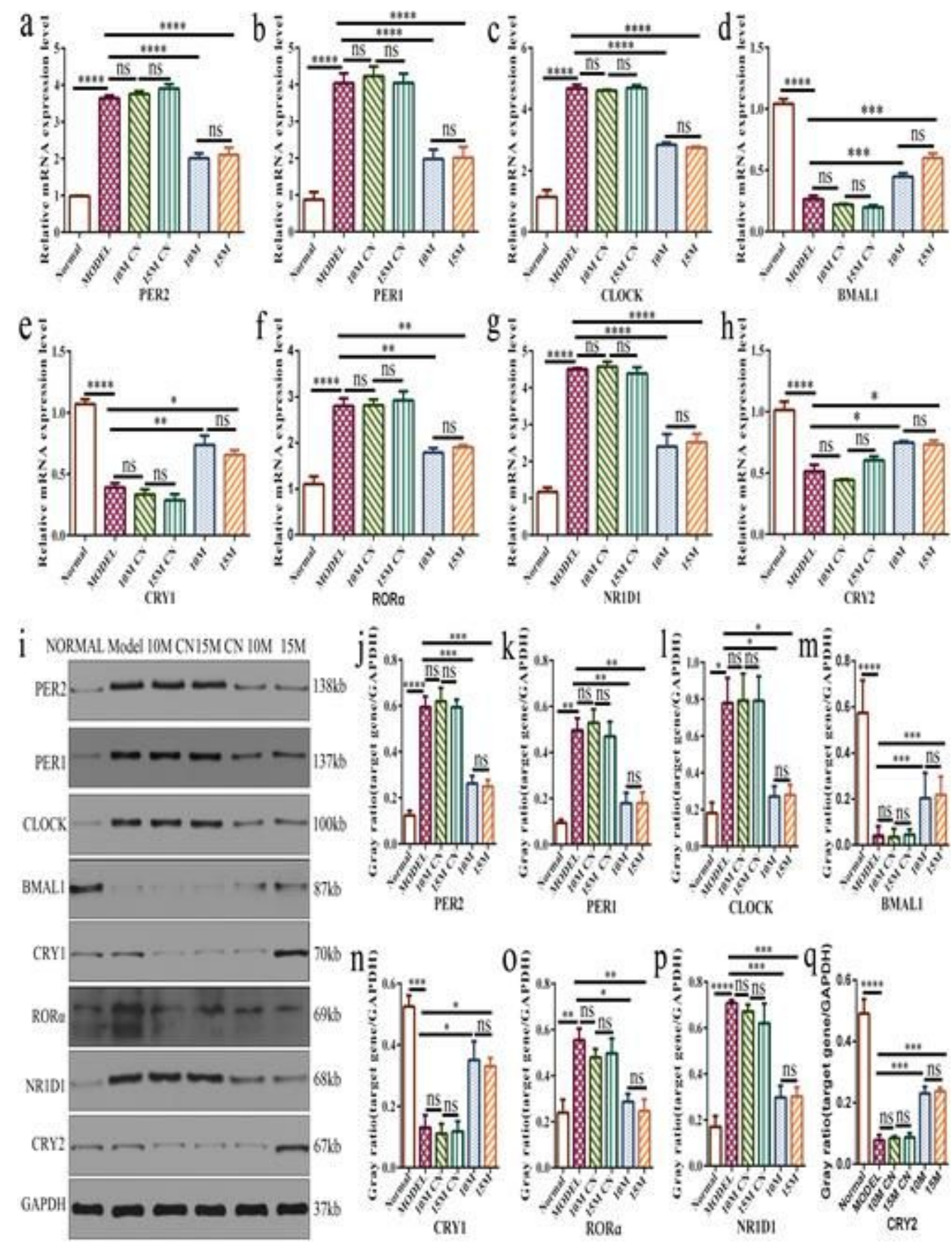

CRYI

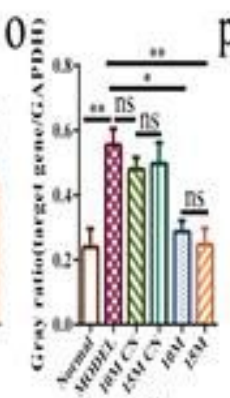

RORa
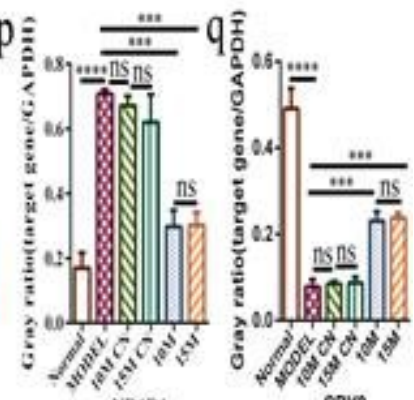

Figure 2

Correlations between CXCL4 sera levels and skin fibrosis and peripheral vasculopathy in SSc. CXCL4 sera levels detected by enzyme-linked immunosorbent assay (ELISA) assay. (A) Correlation of serum CXCL4 levels with the modified Rodnan Skin Score (mRSS) in the combined cohort. (B) Serum CXCL4 levels in SSc patients with digital uclers (DU) and SSc patients without DU. (C) Correlation of DU number and CXCL4 levels. (D) Receiver operating characteristic (ROC) curve for DU onset for prediction of DU. (E) Correlation of patients with a high baseline level of CXCL4 (>2797 ng/ml) and DU onset. (F, G) The nailfold videocapillarscopy (NVC) pattern (F) in SSc patients and the correlation of CXCL4 levels and the mean number of nailfold capillary $(G)(n=58) .(* \star \star p<<0.001)$ 
A

Identification cohort

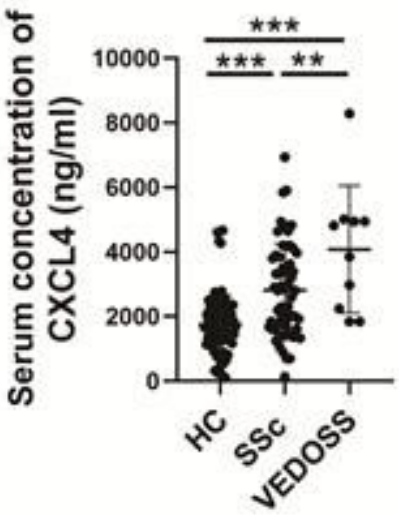

C Combined cohort

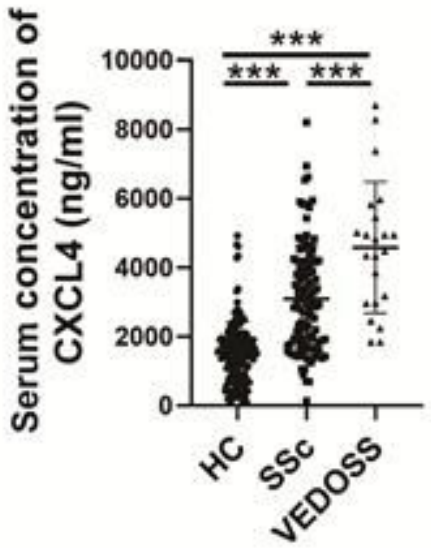

B

\section{Replication cohort}

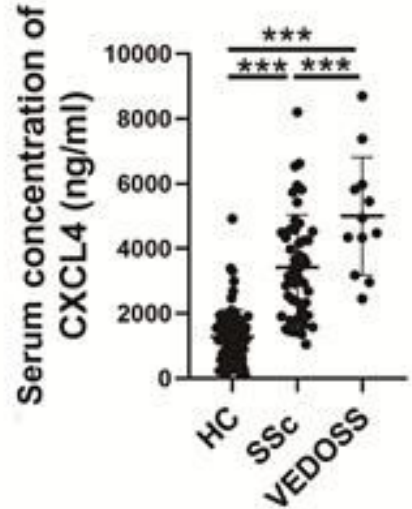

D

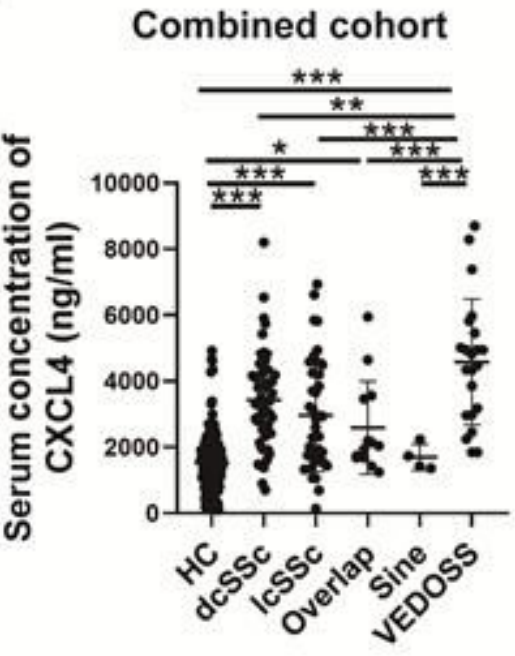

\section{Figure 3}

The gene expression level of endothelin (ET)-1 and friend leukaemia integration factor (Fli)-1 after CXCL4 treatment. The anti-angiogenesis effects of CXCL4 on HUVECs. HUVECs were stimulated with indicate concentration of CXCL4 with or without an anti-CXCL4 antibody $(3 \mu \mathrm{g} / \mathrm{ml})$. HUVECs were pretreated with SSc sera or health sera with or without an anti-CXCL4 antibody $(3 \mu \mathrm{g} / \mathrm{ml})$. (A-D) ET-1 and Fli-1 gene expression levels measured by real-time polymerase chain reaction (RT-qPCR) (A, C) and western blot (B, D). $\left({ }^{\star} \mathrm{P}<0.05,{ }^{\star *} \mathrm{P}<0.01,{ }^{* \star *} \mathrm{P}<0.001\right)$ 

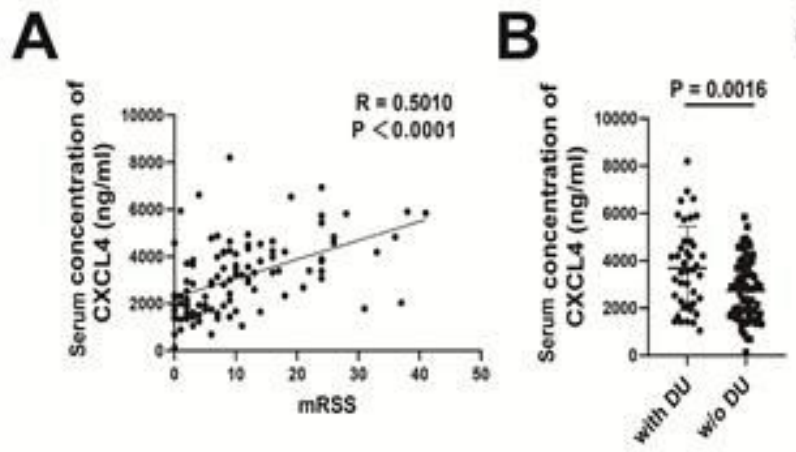

C
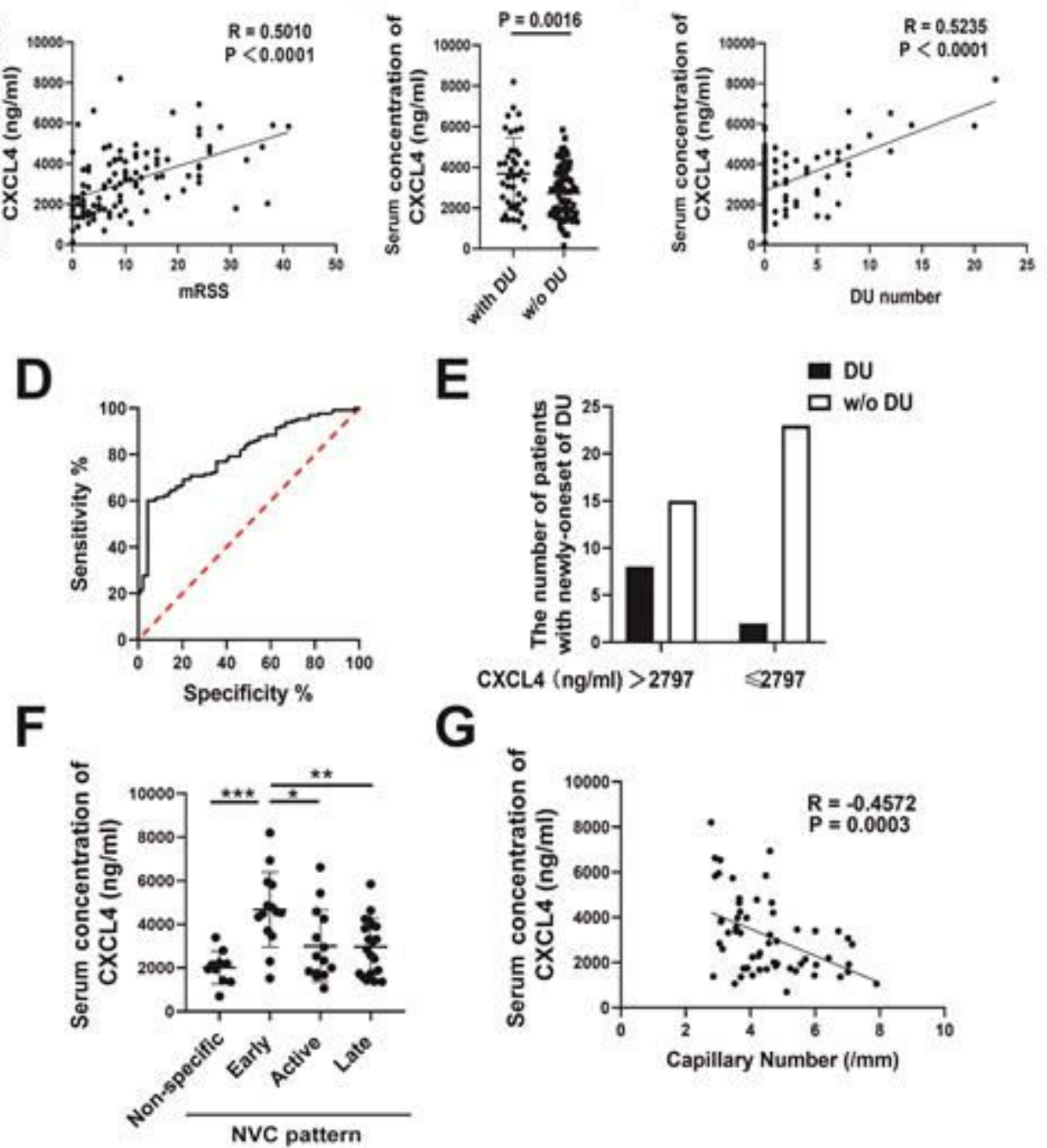

\section{Figure 4}

The activation of C-Abl pathway by CXCL4. (A) HUVECs were exposed to CXCL4 in different concentrations, as indicated. Western blot analysis and quantification of protein levels of c-Abl. (B) HUVECs were stimulated with CXCL4 at indicate time. Western blot analysis and quantification of protein levels of C-Abl. (C-E) HUVECs were stimulated with $20 \mathrm{ng} / \mathrm{ml} \mathrm{CXCL4}$ with or without c-Abl inhibitor ponatinib (10nM). (C) Western blot analysis the protein levels of C-Abl. (D, E) ET-1 and Fli-1 gene expression levels measured by real-time polymerase chain reaction (RT-qPCR) (D) and western blot (E). $\left({ }^{\star} \mathrm{P}<0.05,{ }^{\star *} \mathrm{P}<0.01, * \star * \mathrm{P}<0.001\right)$ 


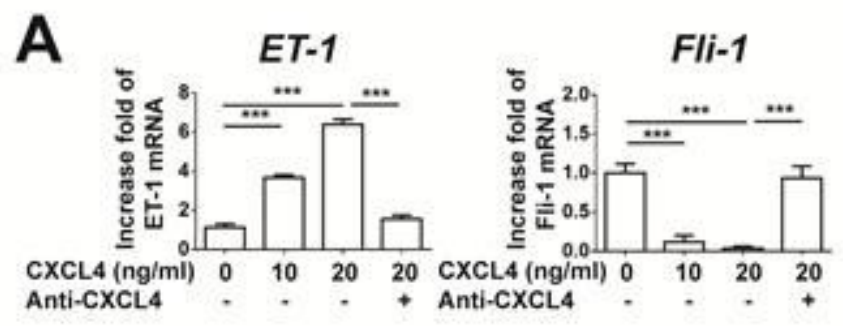

B

ET-1

Fli-1
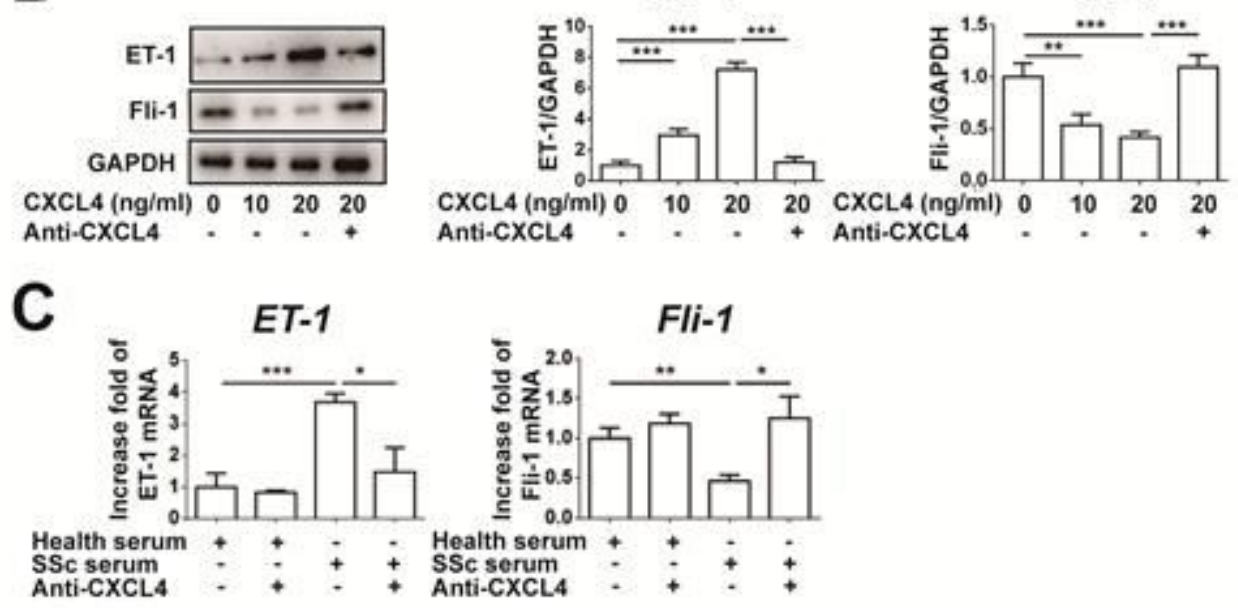

D

$E T-1$

Fli-1

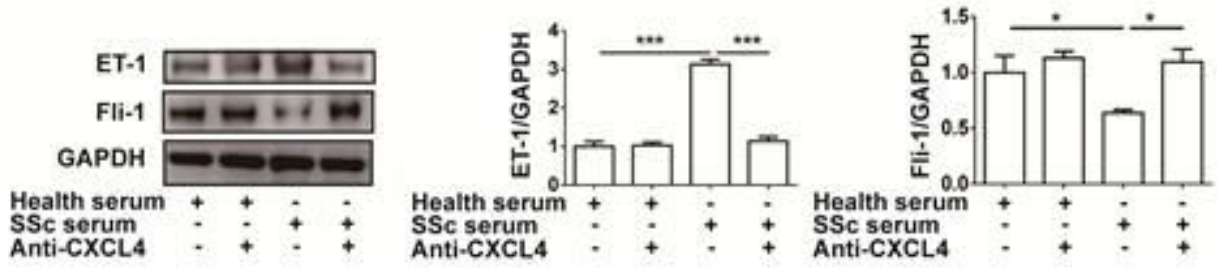

\section{Figure 5}

The involvement of transforming growth factor (TGF)- $\beta$ and platelet-derived growth factor (PDGF) signaling in the anti-angiogenetic effects of CXCL4. (A, B) Cell viability was evaluated by CCK8 assay after 24 hours. (A) HUVECs were treated with TGF- $\beta$ (10ng/ml) for 24 hours, and some cultures were pretreated with SB525334 $(1 \mu \mathrm{M})$, a selective inhibitor of TGF-BR1, or with CXCL4 $(20 \mathrm{ng} / \mathrm{ml})$ with or without an anti-CXCL4 antibody $(3 \mu \mathrm{g} / \mathrm{ml})$. (B) HUVECs were treated with PDGF $(10 \mathrm{ng} / \mathrm{ml})$ for 24 hours, and some cultures were pretreated with blocking PDGFR imatinib $(1 \mu \mathrm{M})$, or with CXCL4 $(20 \mathrm{ng} / \mathrm{ml})$ with or without an anti-CXCL4 antibody $(3 \mu \mathrm{g} / \mathrm{ml}) .(* \star * \mathrm{P}<0.001)$

\section{Supplementary Files}


This is a list of supplementary files associated with this preprint. Click to download.

- Supplementfigure4.tif

- Supplementfigure3.tif

- Supplementfigure2.tif

- Supplementfigure1.tif

- Supplementarymaterials.docx 